\title{
Individualizing the dosage of Methylphenidate in children with attention deficit hyperactivity disorder
}

\author{
Hoda Shirafkan ${ }^{1,2}$, Javad Mahmoudi-Gharaei ${ }^{3}$, Akbar Fotouhi ${ }^{2}$, Seyyed Ali Mozaffarpur ${ }^{4}$, Mehdi Yaseri ${ }^{2 *}$ and \\ Mostafa Hoseini ${ }^{2^{*}}$
}

\begin{abstract}
Background: Attention deficit hyperactivity disorder (ADHD) is one of the most common childhood mental health disorders. Stimulant drugs as the most commonly used treatment and first-line therapy for ADHD have side effects. One of the newest approaches to select the best choices and optimize dosages of medications is personalized medicine.

Methods: This historical cohort study was carried out on the data taken from the period of 2008 to 2015. Eligible subjects were included in the study randomly. We used mixed-effects logistic regression models to personalize the dosage of Methylphenidate (MPH) in ADHD. The patients' heterogeneity was considered using subject-specific random effects, which are treated as the realizations of a stochastic process. To recommend a personalized dosage for a new patient, a two-step procedure was proposed. In the first step, we obtained estimates for population parameters. In the second step, the dosage of the drug for a new patient was updated at each follow-up.

Results: Of the 221 children enrolled in the study, 169 (76.5\%) were male and 52 (23.5\%) were females. The overall mean age at the beginning of the study is 82.5 ( \pm 26.5) months. In multivariable mixed logit model, three variables (severity of $A D H D$, time duration receiving $\mathrm{MPH}$, and dosage of $\mathrm{MPH}$ ) had a significant relationship with improvement. Based on this model the personalized dosage of MPH was obtained.

Conclusions: To determine the dosage of MPH for a new patient, the more the severity of baseline is, the more of an initial dose is required. To recommend the dose in the next times, first, the estimation of random coefficient should be updated. The optimum dose increased when the severity of ADHD increased. Also, the results show that the optimum dose of MPH as one proceeds through the period of treatment will decreased.
\end{abstract}

Keywords: Precision medicine, Tailor medicine, Attention deficit disorder with hyperactivity, Methylphenidate, Mixed-effect models, Longitudinal data

\section{Background}

Attention deficit hyperactivity disorder (ADHD) is one of the most common childhood mental health disorders [1]. The estimated prevalence of ADHD in Iranian children and adolescents is ranging between 2.8 and $19.9 \%$ [2] and ranging from 5 to $12 \%$ in school-aged children worldwide [3].

\footnotetext{
*Correspondence: m.yaseri@gmail.com; mhossein110@yahoo.com ${ }^{2}$ Department of Epidemiology and Biostatistics, School of public health Tehran University of Medical Sciences, Tehran, Iran

Full list of author information is available at the end of the article
}

The etiology of ADHD is multi-factorial [4]. It is a combination of genetic [5, 6] and environmental (e.g., exposure to alcohol or lead, prenatal maternal smoking, prematurity, pregnancy complications, and low birth weight) $[7,8]$ factors. ADHD symptoms (hyperactivity, impulsiveness, and a developmental lack of attention) could cause significant damage in school tasks [9] and in the functions of daily activities [10]. In most children with ADHD, symptoms continue into adolescence and adulthood; it leads to social, occupational and personal dysfunctions [11]; therefore, early diagnosis and 
appropriate treatment could be beneficial [12]. ADHD often accompany other mental and behavioral disorders [9].

Stimulant drugs as the most commonly used treatment and first-line therapy for ADHD have side effects including abdominal pain, nausea, loss of appetite, nervousness, insomnia, compulsive behaviors and movement disorders [13]. Unclear long-term benefits due to undesirable side effects of psychopharmacological treatments, caused scientific society to search for alternative approaches to its treatment [14].

One of the newest approaches to select the best choices and optimize dosages of medications is personalized medicine (PM). PM tries to enable patients to receive an earlier diagnosis and optimal treatments with the least complications and the lowest costs [15]. In PM care, the genetic profile and other information of patients including concurrent medication, allergies, comorbidity, etc., are considered to establish the patient's unique characteristics to tailor the best diagnosis and treatment [15-17].

This study evaluates the relationship between dosage of methylphenidate $(\mathrm{MPH})$ and other important factors with response (improvement) in ADHD patients under the framework of a mixed-effect logit model; then proposes an optimal dose on the basis of the individualized factors of each patient.

\section{Methods}

\section{Study design}

This historical cohort study was carried out on the data taken from the period of 2008 to 2015 on Children with a diagnosis of ADHD who were admitted in the psychiatric clinic as a referral center and a main pediatrics hospital in Iran (the Children's Medical Center in Tehran). The Ethics Committee of the Tehran University of Medical Sciences approved this study. The researchers followed the principles of the Helsinki Declaration.

\section{Participants}

The children with the primary diagnosis of ADHD (based on DSM-IVTR [18] and DSM-V [19]) and the following criteria were entered to the study

1. Being within the age range of 3 to 13 years,

2. Filling the questionnaire for scaling the severity of ADHD (Conners' Parent Rating Scale-revised Short Form (CPRS-R:S)),

3. Having at least one follow-up visit.

The exclusion criteria were as follows:

1. The main diagnosis was another disorder other than ADHD,
2. The children had just one visit (without any follow up),

3. Other drugs instead of MPH were prescribed,

4. The children didn't respond to the treatment up to the last available follow up.(i.e. the MPH have not had any effect on them during the study time)

\section{Data collection}

Of about 5000 available records, based on eligibility criteria, patients' records were assessed randomly. $40 \%$ of the reviewed records did not satisfy inclusion criteria. The sampling was completed when the sample size reached 221.

\section{Study variables}

Gender, birth weight, the age of the first diagnosis, severity of ADHD at baseline, weight per visit, type of comorbidity (if present), time intervals of visits (comparing with the first visit), dose of MPH, consumption of risperidone and fluoxetine were recorded as the basic data of the participants.

To Evaluate and score the severity of ADHD, a reliable Persian version (Cronbach alpha $=0.73$ ) [20] of Conners' Parent Rating Scale-revised Short Form (CPRS-R:S) was used. This scale consisted of 27 items rated from 0 (never) to 3 (very often) [21]. The mean score of at least 1.5 (i.e. crude total score greater than 40) was considered as ADHD. In each follow-up, based on this scale, diagnosis of ADHD was considered as a binary outcome variable $(0=$ meeting the criteria of ADHD (score $>40)$, $1=$ not meeting the criteria of ADHD (score $\leq 40)$ ). It should be declared that not meeting the criteria of ADHD (score $\leq 40$ ) is the therapeutic target.

A milligram per kilogram scale was used to document the dosage of MPH.

\section{Statistical analysis}

The basic characteristics, for quantitative variables, were summarized by mean ( \pm standard deviation), and for qualitative variables, by frequency (percentage). The comparison of the explanatory variables between the two genders was assessed by t-test and nonparametric tests of Mann-Whitney $U$ and chi-square. The significance level was set to $5 \%$ for all tests. The statistical analysis was carried out using $\mathrm{R}$ version 3.5 .1 (package mle4) and STATA version 14.

\section{Multilevel mixed-effect logit model}

We applied a generalized linear mixed model with the binomial response and a logit link,

$$
\log \left(\frac{P\left(Y_{i j}=1\right)}{1-P\left(Y_{i j}=1\right)}\right)=\beta_{0}+X_{i j} \boldsymbol{\beta}+b_{i}+d \log \left(D_{i j}\right)
$$

for $i=1, \ldots, N$ and $j=1, \ldots, n_{i}$, where $Y_{i j}$ indicates the 
binary response variable, the subscript i denoted the study subject. Here $p_{0}$ will symbolize a target value for $\mathrm{P}\left(\mathrm{Y}_{\mathrm{ij}}=1\right) . \mathrm{D}_{\mathrm{ij}}$ is the drug dosage administered for $\mathrm{i}$-th subject and $\mathrm{j}$-th time point, and $\mathrm{d}$ is the corresponding fixed coefficient. In this model $\mathrm{X}_{\mathrm{ij}}$ is the vector of covariates corresponding to fixed-effects parameter vector $\boldsymbol{\beta}$, $\beta_{0}$ is a fixed intercept and $b_{\boldsymbol{i}}$ is a random-effect coefficient for the subject i. we assume it has $\mathrm{N}\left(0, \sigma^{2}\right)$.

The vector of covariates includes gender, age of the onset of ADHD, severity of disease at baseline, birth weight, weight in follow-ups, time interval (the time passed after the commencement of treatment), taking risperidone, taking fluoxetine, being accompanied with affective disorders (mood and bipolar disorders), anxiety disorders (generalized anxiety disorder (GAD), social anxiety disorder (SAD), obsessive-compulsive disorder (OCD), phobia, and anxiety disorder), oppositional defiant disorder (ODD) and, other comorbidities (mental retardation (MR), learning disorder (LD), stutter, Tic, and major depressive disorder (MDD)). The adjusted regression coefficients $(\beta=\ln (O R))$ and their $95 \%$ confidence intervals (CIs) were calculated in Table 3.

To recommend drug dosage for a new patient, a twostep procedure was proposed.

In the first step, we obtained estimates for population parameters $\hat{\boldsymbol{\beta}}, \beta_{0}$ and $\hat{d}$.

In the second step, for the new patient $k$ the estimation for $\hat{b}_{\mathrm{k}}$ was updated at each time as below.

1. At time $\mathrm{t}_{1}$, set $\hat{b}_{\mathrm{k}, 0}=0$ and make the initial dose

$$
D_{k 1}=\exp \left\{\frac{\operatorname{logit}\left(p_{0}\right)-\beta_{0}-X_{k 1} \hat{\boldsymbol{\beta}}_{-} \hat{b}_{k, 0}}{\hat{d}}\right\}
$$

where the $p_{0}$ is calculated using by predicting $\mathrm{P}\left(\mathrm{Y}_{\mathrm{ij}}=1\right)$. In order to predict $\mathrm{P}\left(\mathrm{Y}_{\mathrm{ij}}=1\right)$, we used all available responses, and then the 90th percentile of these probabilities was determined.

2. For time $t_{n}(n>1)$, based on the values of the covariates of the previous time of this individual the estimate $\hat{b}_{k, n-1}$ was obtained, the proposed dose for time $t_{n}$ was obtained from the following equation

$$
D_{k n}=\exp \left\{\frac{\operatorname{logit}\left(p_{0}\right)-\hat{\beta}_{0}-X_{k n} \hat{\boldsymbol{\beta}}-\hat{b}_{k, n-1}}{\hat{d}}\right\}
$$

in which $b_{i}$ is predicted by the adaptive Gauss-Hermite approximation to the log-likelihood.

\section{Results}

Evaluating 298 records, the sample size of 221 was achieved that means 77 records didn't meet the eligibility criteria.

This 77 records were excluded because CPRS-R:S was not correctly completed in 22 records, the main complaint was not ADHD in 19 records (five ODD, three $\mathrm{MR}$, three communication disorder, two GAD, two LD, one SAD, one autism, one MDD, and one tic), other drugs were prescribed instead of MPH for 16 records, 14 records did not have any follow up, and for 6 records the age was less than 3 years old.

Of the 221 children enrolled in the study, 169 (76.47\%) were male and $52(23.53 \%)$ were female. The basic characteristics of patients between two sexes are not significantly different. The basic characteristics of these individuals are shown in Table 1.

In this study, six children had attention deficit disorder (ADD) (two females and four males) and 143 children had comorbidities with ADHD (55 anxiety disorders, 43 ODD, 6 affective disorders, and 39 had other comorbidities). These comorbidities were found to be as follows: anxiety disorder (GAD: 33 (14.93\%), SAD: 18 (8.14\%), Phobia: 6 (2.71\%), OCD: 8 (3.62\%), Anxiety: 7 (3.17\%)); affective disorder (Mood: 5 (2.26\%), Bipolar: 1 (0.45\%)); Mental retardation: 4 (1.81\%); Learning disorder: 20 (9.05\%); TIC: 11 (4.98\%); MDD: 3 (1.36\%); Stuttery: 1 (0.45\%); ODD: 43 (19.45\%).

The overall improvement rate was calculated to be $62.70 \%$, and no significant difference $(p=0.251)$ was observed between males (61.63\%) and females (65.77\%).

In the univariable mixed-logit analysis, four variables had significant relations with improvement (not meeting criteria of ADHD) including the weight of the patients in each follow-up, the severity of ADHD at the baseline, time interval of receiving the MPH, and dosage of MPH. These variables were imported to the multivariable mixed-logit model. As a result of the analysis based on this model, three variables (except weight) had a significant relationship with improvement. (Table 2).

In order to calculate the optimal dose, we use the coefficient of the final multivariable random effect model (Table 3).

The target value for $P\left(Y_{i j}=1\right)$ is $p_{0}=0.9866$. The histogram of predicted values of $\mathrm{P}\left(\mathrm{Y}_{\mathrm{ij}}=1\right)$ and random effect are shown in Fig. 1. To determining the dosage of MPH for a new patient $(\mathrm{k})$ at the first visit, the initial dose can be calculated as follows:

$$
D_{k 1}=\exp \left\{\frac{4.2990-1.9377+0.0512 \times(\text { severity }-51.3817)-\hat{b}_{k, 0}}{0.8610}\right\}
$$

Where 4.2990 is the logit of the predicted value $p_{0}$, 1.9377 is the estimate of fixed intercept, and 51.3817 is 
Table 1 The basic characteristics of children with ADHD

\begin{tabular}{|c|c|c|c|c|}
\hline Variable & Overall $(n=221)$ & Female $(n=52)$ & Male $(n=169)$ & $p$-value \\
\hline Age at baseline (month; mean \pm SD) & $82.53 \pm 26.47$ & $85.65 \pm 28.22$ & $81.57 \pm 25.92$ & 0.332 \\
\hline Birth weight ( $\mathrm{kg}$; mean $\pm \mathrm{SD}$ ) & $3.09 \pm 0.56$ & $3.07 \pm 0.57$ & $3.09 \pm 0.56$ & 0.815 \\
\hline Low birth weight ${ }^{\mathrm{a}}, \mathrm{n}(\%)$ & $36(16.3 \%)$ & $7(13.5 \%)$ & $29(17.2 \%)$ & 0.528 \\
\hline Weight at baseline (kg; mean \pm SD) & $30.95 \pm 5.62$ & $25.65 \pm 9.66$ & $24.97 \pm 7.28$ & 0.191 \\
\hline Period of treatment (month; mean $\pm \mathrm{SD}$ ) & $22.42 \pm 15.19$ & $20.13 \pm 14.46$ & $23.12 \pm 15.38$ & 0.216 \\
\hline Severity of ADHD at baseline (mean $\pm S D$ ) & $51.38 \pm 10.82$ & $48.96 \pm 9.03$ & $52.12 \pm 11.23$ & 0.065 \\
\hline Number of follow-ups (mean \pm SD) & $4.94 \pm 2.83$ & $4.69 \pm 2.65$ & $5.01 \pm 2.89$ & 0.478 \\
\hline
\end{tabular}

${ }^{a}$ Children with a birth weight of lower than $2500 \mathrm{~g}$ were considered as having a low birth weight

the mean of the severity of ADHD at baseline. The diagram of this equation is shown in Fig. 2.

Also at the $n$-th time point (follow-up), the dosage can be calculated based on the following formula:

$$
D_{k n}=\exp \left\{\frac{\operatorname{logit}\left(p_{0}\right)-1.9377+0.0512 \times(\text { severity }-51.3817)-0.0800 \times \text { time }-\hat{b}_{k, n-1}}{0.8610}\right\}
$$

Where $p_{0}$ is the target probability of improvement, $s e$ verity is the severity of ADHD at baseline (based on CPRS-R:S) and time is the number of months on treatment. The diagram of the dosage recommendation for different time points is shown in Fig. 3. In order to illustrate the above relationship, the optimum dosage is obtained for some hypothetical data (Table 4). Furthermore, the computer code for predicting $b_{i}$ and for computing the optimal dosage is available in Additional file 1.

\section{Discussion}

In this study, the clinical severity at baseline, logarithm of dosage of $\mathrm{MPH}$, and time duration of receiving the MPH were associated with improvement of ADHD.

The dosage of MPH in logarithmic scale had a meaningful association with improving from ADHD, in which the chance of improvement increased 2.36 times as one unit adding in the dosage of $\mathrm{MPH}$ in the logarithm scale.

According to multivariable random effect logistic model (Table 2), the odds ratio of severity is 0.9500 , therefore with increasing one unit in severity, the chance of improvement decreased. Also, the odds ratio of time is 1.0833, therefore increasing one month receiving $\mathrm{MPH}$, the chance of improvement increased.

Table 2 Association between explanatory variables and improvement of ADHD

\begin{tabular}{|c|c|c|c|c|c|}
\hline \multirow{2}{*}{ Fixed effects } & \multirow[b]{2}{*}{ Covariates } & \multicolumn{2}{|l|}{ Univariable Analysis } & \multicolumn{2}{|l|}{ Multivariable Analysis } \\
\hline & & OR $(95 \% \mathrm{Cl})$ & P-Value & OR $(95 \% \mathrm{Cl})$ & $P$-Value \\
\hline & Sex (Male) & $0.8358(0.5684,1.2289)$ & 0.361 & - & - \\
\hline & Age (month) & $0.9991(0.9829,1.0053)$ & 0.795 & - & - \\
\hline & Weight (kg) & $1.0270(1.0084,1.0459)$ & $0.004^{*}$ & - & - \\
\hline & Birthweight (kg) & $0.8265(0.6149,1.1109)$ & 0.212 & - & - \\
\hline & Time interval (month) & $1.0844(1.0677,1.1014)$ & $<0.001^{*}$ & $1.0833(1.0661,1.1007)$ & $<0.001^{*}$ \\
\hline & Severity ${ }^{a}$ & $0.9597(0.9462,0.9734)$ & $<0.001^{*}$ & $0.9500(0.9305,0.9699)$ & $<0.001^{*}$ \\
\hline & Log Dose MPH, (mg per kg) & $2.2766(1.6855,3.0750)$ & $<0.001^{*}$ & $2.3653(1.6602,3.3699)$ & $<0.001^{*}$ \\
\hline & Taking risperidone & $0.9035(0.6720,1.2150)$ & 0.503 & - & - \\
\hline & Taking Fluoxetine & $0.7398(0.4524,1.2097)$ & 0.227 & - & - \\
\hline & ODD & $0.6842(0.4648,1.0070)$ & 0.064 & - & - \\
\hline & Mood disorder ${ }^{\mathrm{b}}$ & $0.6846(0.2952,1.5873)$ & 0.379 & - & - \\
\hline & Anxiety disorder ${ }^{c}$ & $1.9619(0.7667,1.5672)$ & 0.614 & - & - \\
\hline & Other comorbidities ${ }^{d}$ & $0.9692(0.8631,1.0883)$ & 0.587 & - & - \\
\hline \multirow{2}{*}{\multicolumn{2}{|c|}{ Random intercept }} & - & \multicolumn{2}{|c|}{ Variance estimation } & $(95 \% \mathrm{Cl})$ \\
\hline & & - & \multicolumn{2}{|l|}{1.452} & $(1.2931,1.6108)$ \\
\hline
\end{tabular}


Table 3 Final multivariable random effect model

\begin{tabular}{|c|c|c|c|c|}
\hline & Covariates & Coefficient & $(95 \% \mathrm{Cl})$ & $P$-Value \\
\hline \multirow[t]{4}{*}{ Fixed effects } & Intercept & 1.9377 & $(0.9286,2.9469)$ & $<0.001^{*}$ \\
\hline & Time interval (month) & 0.0800 & $(0.0640,0.0959)$ & $<0.001^{*}$ \\
\hline & Severity & -0.0512 & $(-0.0720,-0.030)$ & $<0.001^{*}$ \\
\hline & Log Dose MPH, (mg per kg) & 0.8610 & $(0.5069,1.2149)$ & $<0.001^{*}$ \\
\hline \multirow[t]{2}{*}{ Random intercept } & Variance estimation & & $(95 \% \mathrm{Cl})$ & \\
\hline & 1.452 & & $(1.2931,1.6108)$ & \\
\hline
\end{tabular}

*Significant at 0.05

As ADHD can cause social, emotional and economic failure and also increased mortality [22], pharmacological treatment in many cases is inevitable. On the other hand MPH as the most common drug, has an important complication, so trying to prescribe the optimum dose for each patient is a considerable achievement.

In this study, although the rate of males and females was not the same, as the demographic data were not different, we didn't make subgroups of males and females to analyze the data.

We used generalized linear mixed models (GLMMs) method to personalize the dosage of MPH in ADHD. Generalized linear models (GLMs) are used to investigate and analyze the relationship between clinical, demographic, and genetic covariates on the response variable such as patient recovery. But these models aggregately study the relationships and characteristics of individuals. To investigate the relationships of the response with the unique characteristics of the studied subjects, another family of statistical models, usually called GLMMs (or random-effects (REs) linear models) is used. Using these models can be a valuable tool and a comprehensive conceptual framework for the development of personalized medicine [23].
The fact that GLMMs have the concepts that allow explaining patient populations as a whole (the fixed effects) and, simultaneously, concepts that allow describing patients as individuals (the REs) suggests that these models include the key ideas for providing PM with a precise statistical language $[24,25]$. Thus, the variation of random components are not only due to a mathematical artifact control for patients' heterogeneity but also the consequence of actual variation in the biological and environmental factors making humans develop as individuals [26]. Hence, both biological and statistical evidence supports the development of a methodological tool for PM based on GLMMs.

In this study we proposed a drug dosage individualization procedure than could be considered as an extension of the individualization algorithm proposed by Diaz et al. for continuous responses to dichotomous responses [25, 27].

Based on the result of this study, in order to determine the dosage of MPH for a new patient (initial dose), the greater the severity of baseline is, the higher the initial dosage is required.

To recommend the dosage in the next times, first, due to the information of the patient the random coefficient
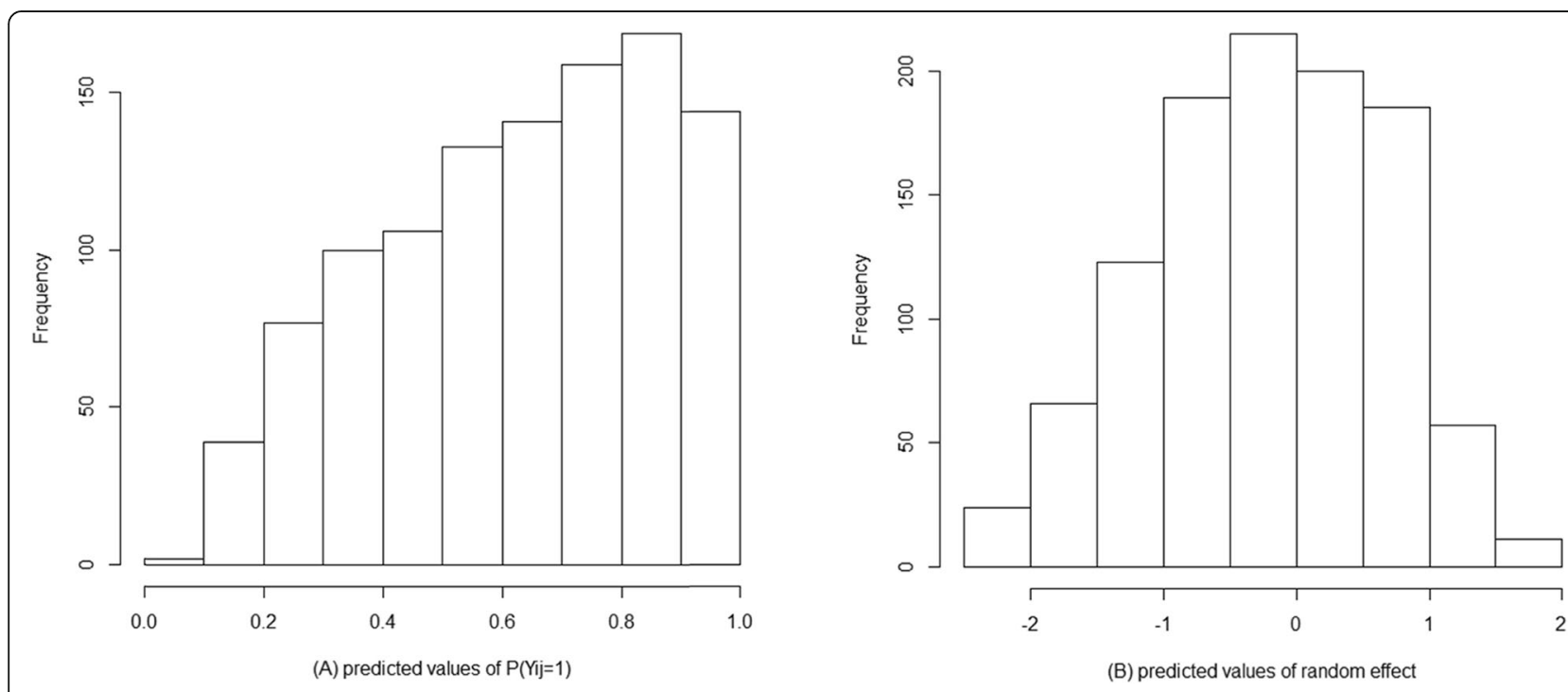

Fig. 1 The histogram of $(\mathbf{a})$ the predicted value for $P\left(Y_{i j}=1\right)$ at the last visit and $(\mathbf{b})$ the predicted value for the random effect $\left(\hat{b}_{i}\right)$ 


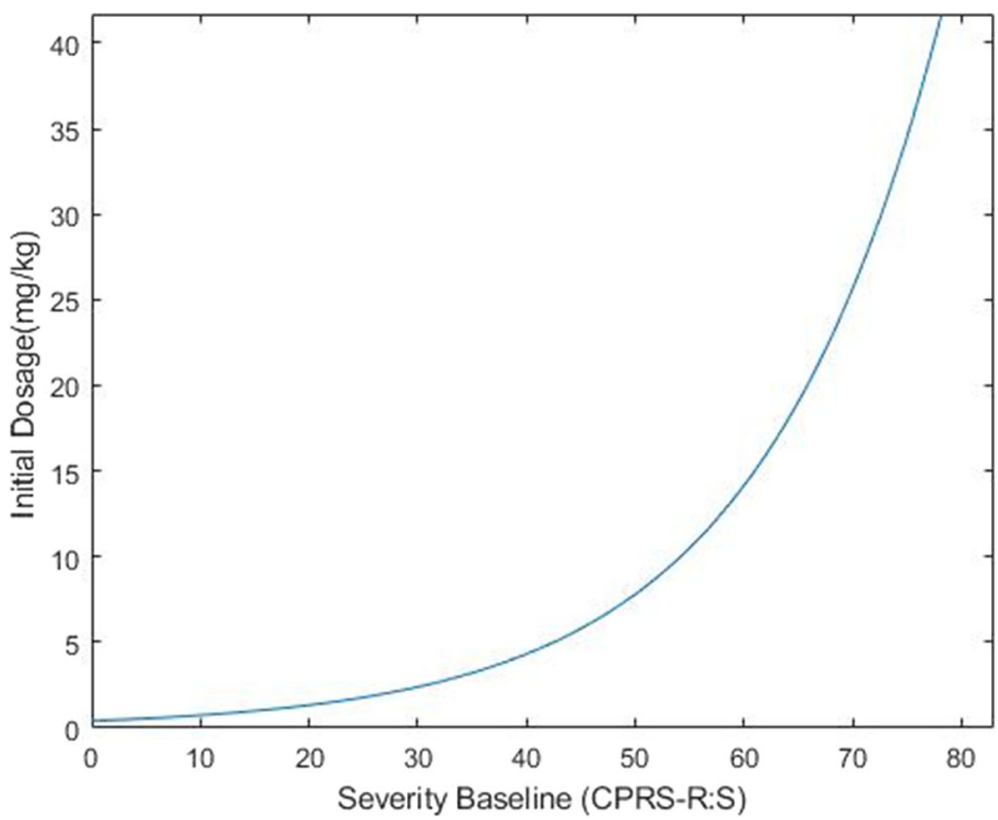

Fig. 2 The optimum initial dosage of MPH in ADHD, based of severity of baseline (CPRS-R:S) The figure represents average patients

should be updated then the dosage should be calculated for him/her. According to the results of this study, in patients with the same severity of disease and same response to the treatment, with increasing the period of receiving $\mathrm{MPH}$, the optimum dose of $\mathrm{MPH}$ decreased on the $\log$ scale by the rate of $0.08 \mathrm{mg} / \mathrm{kg}$. Furthermore, the more the severity of ADHD is, the higher of the optimum dose is needed, i.e. considering that response to the treatment is similar among patients, at the same time the optimum dose of MPH increased by the rate of $0.06 \mathrm{mg} / \mathrm{kg}$ as the severity of ADHD based on CPRS-R:S increased. As seen in Fig. 1, for an average patient, the

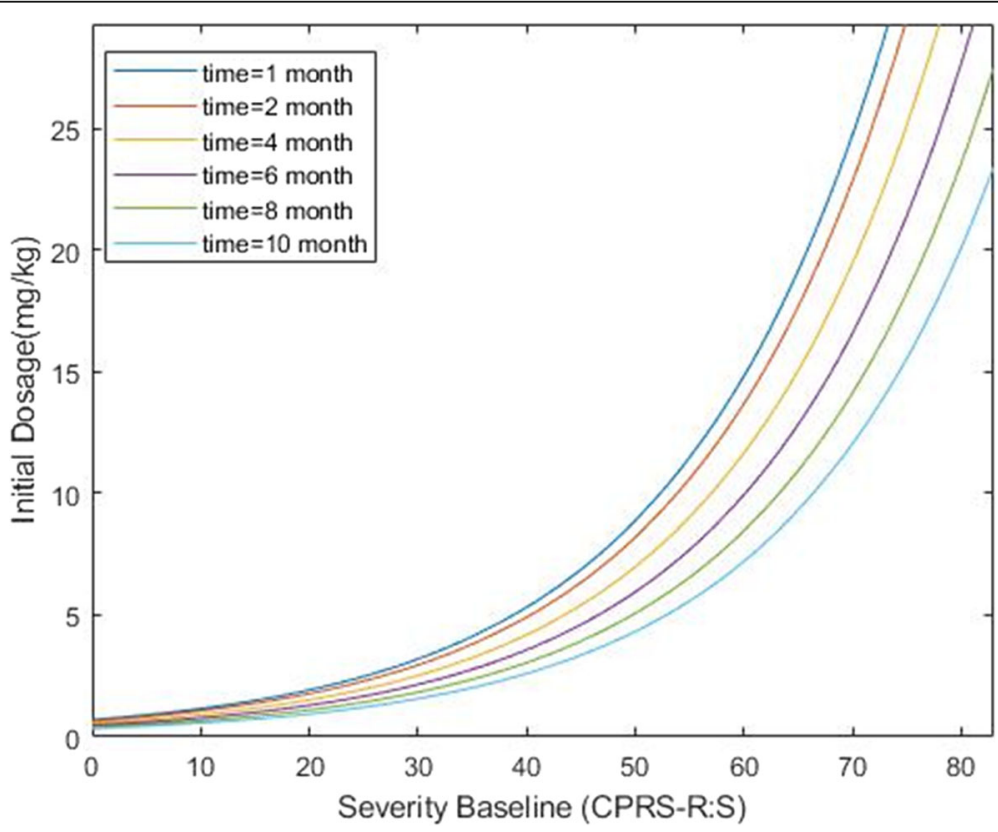

Fig. 3 The optimum dosage of MPH in ADHD, based on severity of baseline for different time points. This figure corresponds to the average patients 
Table 4 Recommended dosage for hypothetical patients

\begin{tabular}{llllllll}
\hline Patient ID & weight & Severity of baseline & Time (month) & Baseline response & Dichotomized responses & $\hat{b}_{i}$ & ${\text { Recommended dose }(\mathrm{mg} / \mathrm{kg})^{\mathrm{a}}}^{2}$ \\
\hline 1 & 24 & 56 & 1 & 45 & 0 & -0.1647 & 0.1638 \\
1 & 24 & 56 & 2 & 42 & 0,0 & -0.1651 & 0.1247 \\
1 & 24 & 56 & 4 & 39 & $0,0,1$ & -0.1690 & 0.0871 \\
2 & 23 & 78 & 1 & 67 & 0 & -0.1497 & 0.6023 \\
2 & 23 & 78 & 2 & 65 & 0,0 & -0.1449 & 0.4781 \\
2 & 23 & 78 & 5 & 39 & $0,0,1$ & -0.1456 & 0.0773 \\
2 & 23 & 78 & 6 & 30 & $0,0,1,1$ & -0.1439 & 0.0412 \\
\hline
\end{tabular}

${ }^{\mathrm{a}}$ : the recommended dose is predicted based on the formula (5)

optimal dose with higher degree of severity is increased. Also, the optimal dose of MPH decreased when the time duration of receiving MPH increased.

To best of our knowledge, few studies on factors affecting treatment in ADHD have been published. In a Cochrane systematic review by Osland et al. in 2018, mentioned 3 studies that evaluated the MPH in ADHD [28]. In a crossover trial, children were randomized to three weeks each of $\mathrm{MPH}$, dextroamphetamine, and placebo. MPH significantly decreased hyperactivity at all doses [29]. In this study, they did not propose any optimum dose of MPH. Gadow KD et al. mentioned that treatment with 3 doses $(0.1,0.3$ and $0.5 \mathrm{mg} / \mathrm{kg}$ ) of MPH resulted in best improvement of ADHD with no significant differences between $0.1-\mathrm{mg} / \mathrm{kg}$ and $0.3-$ $\mathrm{mg} / \mathrm{kg}$ dose on any of dependent measures [30].

In another study evaluating the treatment of ADHD in children with tic A, The dosage of average $25.9 \mathrm{mg} / \mathrm{d}$ of MPH was proposed for ADHD [31]. Therefore it seems that no study had been done to evaluate the effective factors to estimate the best dosage.

The strengths of this study include its conduct with a large and diverse sample of children with the main diagnosis of ADHD and the mean follow up period of 22.42 month. Also, we used the CPRS-R:S version of it because of its reliability and validity in the Persian version [20]. Furthermore, we used GLMM to individualize the dosage of MPH. Since participants were randomly recruited in this study across a referral hospital; therefore samples may not represent the population of ADHD children, hence it is proposed that a multicenter study could be done to better generalizability of the findings. However, full consideration of all factors that may have an impact on the improvement of ADHD, such as those related to the social economic status of children's family, environmental factors like possible stresses that may be encountered by any patient, was outside the scope of this paper and hence these may represent confounding variables. Assessing factors associated with improvement for each comorbidity separately was also outside the scope of this paper. Nevertheless, the results of this study provide an individualized dosage for each patient due to factors affecting their improvement.

\section{Conclusions}

In this paper, we propose a two-step procedure to make personalized dosage recommendations. The key idea of this method is to utilize subject-specific random effects from longitudinal responses specifying unique individual information that could contribute to post-treatment outcomes. In order to determine the dosage of $\mathrm{MPH}$ for a new patient, the greater the severity of baseline is, the higher the initial dose is required. Furthermore, in the next visits, to recommend the dose, the estimation of the random coefficients should be updated. The optimum dose increased when the severity of ADHD increased. Also, the results show that the optimum dose of $\mathrm{MPH}$ as one proceeds through the period of treatment, will decrease.

\section{Supplementary information}

Supplementary information accompanies this paper at https://doi.org/10 1186/s12874-020-00934-y.

\section{Additional file 1.}

Abbreviations

ADD: Attention deficit disorder; ADHD: Attention deficit hyperactivity disorder; CPRS-R:S: Conners' Parent Rating Scale-revised Short Form; CRS: Conners' Rating Scales; GAD: Generalized anxiety disorder; GLM: Generalized linear models; GLMM: Generalized linear mixed models; LD: Learning disorder; MDD: Major depressive disorder; MPH: Methylphenidate; MR: Mental retard; OCD: Obsessive-compulsive disorder; ODD: Oppositional defiant disorder; PM: Personalized medicine; Re: Random-effect; SAD: Social anxiety disorder

\section{Acknowledgments}

The authors would like to express their thanks to the staff of pediatric psychological clinic of the Children's Medical Center in Tehran, Iran. Also, their appreciation and gratitude go to Dr. Mohammad Ali Shams for reviewing the manuscript and revising the language of this article.

\section{Authors' contributions}

HS: acquisition and interpretation of data, study concept and design, study management and drafting of the manuscript. MH and MY: study concept and design, acquisition and interpretation of data and critical revision of the manuscript. AF, JM, and SAM: study concept and design, interpretation of data and critical revision of the manuscript. The authors read and approved the final manuscript.

\section{Funding}

This research did not receive any specific grant from any agency in the public, commercial, or not-for-profit sector. 


\section{Availability of data and materials}

The datasets used and/or analyzed during the current study are available from the corresponding author on reasonable request.

\section{Ethics approval and consent to participate}

This study was approved by the Ethics Committee of the Tehran University of Medical Sciences.

\section{Consent for publication}

Not applicable.

\section{Competing interests}

The authors declare that they have no competing interests.

\section{Author details}

'Social Determinants of Health (SDH) Research Centre, Research Institute for Health, Babol University of Medical Sciences, Babol, Iran. ${ }^{2}$ Department of Epidemiology and Biostatistics, School of public health, Tehran University of Medical Sciences, Tehran, Iran. ${ }^{3}$ Psychiatry and Psychology Research Center, Roozbeh Hospital, Tehran University of Medical Sciences, Tehran, Iran. ${ }^{4}$ Traditional Medicine and History of Medical Sciences Research Center, Health Research Institute, Babol University of Medical Sciences, Babol, Iran.

\section{Received: 28 March 2019 Accepted: 19 February 2020}

Published online: 11 March 2020

\section{References}

1. Rowland AS, Lesesne CA, Abramowitz AJ. The epidemiology of attentiondeficit/hyperactivity disorder (ADHD): a public health view. Ment Retard Dev Disabil Res Rev. 2002;8(3):162-70.

2. Shooshtary MH, Chimeh N, Najafi M, Mohamadi MR, Yousefi-Nouraie R, Rahimi-Mvaghar A. The prevalence of attention deficit hyperactivity disorder in Iran: a systematic review. Iran J Psychiatry. 2010;5(3):88

3. Raman SR, Man KK, Bahmanyar S, Berard A, Bilder S, Boukhris T, et al. Trends in attention-deficit hyperactivity disorder medication use: a retrospective observational study using population-based databases. Lancet Psychiatry. 2018;5(10):824-35

4. Antony A. Study of factors influencing treatment adherence in childhood attention deficit hyperactivity disorder in a tertiary healthcare facility. Indian J Psychol Med. 2016;38(1):20.

5. Demontis D, Walters RK, Martin J, Mattheisen M, Als TD, Agerbo E, et al. Discovery of the first genome-wide significant risk loci for attention deficit/ hyperactivity disorder. Nat Genet. 2019:51(1):63.

6. Baht M, Grizenko N, Ben-Amor L, Joober R. Obstetric complications in children with attention deficit/hyperactivity disorder and learning disability. McGill J Med. 2005;8(2):109.

7. Millichap JG. Etiologic classification of attention-deficit/hyperactivity disorder. Pediatrics. 2008;121(2):e358-e65.

8. Cerrillo-Urbina AJ, García-Hermoso A, Martínez-Vizcaíno V, Pardo-Guijarro MJ, Ruiz-Hermosa A, Sánchez-López M. Prevalence of probable attention-deficit/ hyperactivity disorder symptoms: result from a Spanish sample of children. BMC Pediatr. 2018;18(1):111.

9. Spencer TJ. ADHD and comorbidity in childhood. J Clin Psychiatry. 2006;67: 27-31.

10. Courtabessis E, Pupier F, Surig L, Picot M-C, Nogué E, Macioce V, et al. Clinical factors associated with decision to recommend methylphenidate treatment for children with ADHD in France. Eur Child Adolescent Psychiatry, 2018:27(3):367-76

11. Resnick RJ. Attention deficit hyperactivity disorder in teens and adults: they don't all outgrow it. J Clin Psychol. 2005;61(5):529-33.

12. Polanczyk G, De Lima MS, Horta BL, Biederman J, Rohde LA. The worldwide prevalence of ADHD: a systematic review and metaregression analysis. Am J Psychiatr. 2007;164(6):942-8.

13. Kim B-N, Kim Y-N, Cheong U-S, Kim J-W, Hwang J-W, Shin M-S, et al. Switching from methylphenidate-immediate release (MPH-IR) to methylphenidate-OROS (OROS-MPH): a multi-center, open-label study in Korea. Clin Psychopharmacol Neurosci. 2011;9(1):29.

14. Cagigal C, Silva T, Jesus M, Silva C. Does diet affect the symptoms of ADHD? Curr Pharm Biotechnol. 2019;20(2):130-36. https://doi.org/10.2174/ 1389201019666180925140733.
15. Vogenberg FR, Barash Cl, Pursel M. Personalized medicine: part 1: evolution and development into theranostics. Pharm Ther. 2010;35(10):560.

16. Guidi GC, Lippi G. Will "personalized medicine" need personalized laboratory approach? Clin Chim Acta. 2009:400(1-2):25-9.

17. Alemi F, Erdman H, Griva I, Evans $\mathrm{CH}$. Improved statistical methods are needed to advance personalized medicine. Open Transl Med J. 2009;1:16.

18. Guze SB. Diagnostic and Statistical Manual of Mental Disorders, 4th ed. (DSM-IV). 2006. https://doi.org/10.1176/ajp.152.8.1228.

19. Association AP. Diagnostic and statistical manual of mental disorders, 5 th edition (DSM-5). Am Psychiatric Assoc. https://doi.org/10.1176/appi.books. 9780890425596

20. Shahabian A, Shahim S, Bashash L, Yousefi F. Psychometry, factor analysis, and reliability of Conner rating scale for children 6-11 in shiraz: parents short form. Q J Psychol Stud. 2007;3(3):97-120 (In Persian).

21. Conners C. Conners' rating scales-revised. North Tonawanda, New York: Multi-Health Systems. Inc; 1997.

22. Dalsgaard S, Østergaard SD, Leckman JF, Mortensen PB, Pedersen MG Mortality in children, adolescents, and adults with attention deficit hyperactivity disorder: a nationwide cohort study. Lancet. 2015;385(9983): 2190-6.

23. Diaz FJ. Measuring the individual benefit of a medical or behavioral treatment using generalized linear mixed-effects models. Stat Med. 2016; 35(23):4077-92.

24. Diaz FJ, Yeh H-W, de Leon J. Role of statistical random-effects linear models in personalized medicine. Current Pharmacogenomics and Personalized Medicine (Formerly Current Pharmacogenomics). 2012;10(1):22-32.

25. Diaz FJ, Cogollo MR, Spina E, Santoro V, Rendon DM, de Leon J. Drug dosage individualization based on a random-effects linear model. J Biopharm Stat. 2012;22(3):463-84.

26. Diaz FJ, Santoro V, Spina E, Cogollo M, Rivera T, Botts S, et al. Estimating the size of the effects of co-medications on plasma clozapine concentrations using a model that controls for clozapine doses and confounding variables. Pharmacopsychiatry. 2008;41(03):81-91.

27. Diaz FJ, Rivera TE, Josiassen RC, Jd L. Individualizing drug dosage by using a random intercept linear model. Stat Med. 2007;26(9):2052-73.

28. Osland ST, Steeves TD, Pringsheim T. Pharmacological treatment for attention deficit hyperactivity disorder (ADHD) in children with comorbid tic disorders. Cochrane Database Syst Rev. 2018;6:CD007990.

29. Castellanos FX, Giedd JN, Elia J, Marsh WL, Ritchie GF, Hamburger SD, et al. Controlled stimulant treatment of ADHD and comorbid Tourette's syndrome: effects of stimulant and dose. J Am Acad Child Adolesc Psychiatry. 1997;36(5):589-96.

30. Gadow KD, Nolan E, Sprafkin J, Sverd J. School observations of children with attention-deficit hyperactivity disorder and comorbid tic disorder: effects of methylphenidate treatment. J Dev Behav Pediatr. 1995;16(3):167-76.

31. Tourette's Syndrome Study G. Treatment of ADHD in children with tics: a randomized controlled trial. Neurology. 2002;58(4):527-36.

\section{Publisher's Note}

Springer Nature remains neutral with regard to jurisdictional claims in published maps and institutional affiliations.
Ready to submit your research? Choose BMC and benefit from:

- fast, convenient online submission

- thorough peer review by experienced researchers in your field

- rapid publication on acceptance

- support for research data, including large and complex data types

- gold Open Access which fosters wider collaboration and increased citations

- maximum visibility for your research: over $100 \mathrm{M}$ website views per year

At $\mathrm{BMC}$, research is always in progress.

Learn more biomedcentral.com/submissions 